\title{
Proposed EU changes to competition laws
}

\author{
by Professor Christopher Bovis
}

Fundamental changes are proposed in relation to competition law in Europe. Professor Christopher Bovis, Jean Monnet Chair of European and Business law at the University of Central Lancashire, analyses present and future procedural competition law.

\section{$\mathrm{T}$} The European Union has proposed a series of fundamental changes in relation to procedural competition law. These changes would result in a jurisdictional shift in the application and enforcement of competition law from the sole and exclusive authority of the European Commission and the European Court of Justice (ECJ) to a parallel and concurrent jurisdiction with domestic competition authorities and national courts. At the heart of the Commission's proposals is the valid argument that its relevant department (DG Competition) can no longer cope effectively with the demands of the EU when applying and enforcing competition law. Procedural logistics and the administrative overload imposed on the Commission by the current system of notifications and authorisations appear to be the main driver for the reforms. The Commission has openly challenged the adequacy of procedural competition laws for the current and future shape of the EU and their esoteric relation with substantive anti-trust rules stipulated in the Treaties.

The Commission is oriented towards a decentralised application and enforcement of EU competition law and policy through a system that would replace the notification and authorisation of restrictive agreements with block exemptions. It is determined to press ahead with reforms. A number of member states, commentators, academics and practitioners view procedural changes as necessary modernisation of a system that was designed almost 40 years ago. This article analyses the Commission's reform proposals by assessing the current procedural competition rules and their impact on the EU competition law and policy.

\section{THE EU COMPETITION LAWS: ARE UNIFORMITY AND CENTRALISATION INDICATIONS OF AN IRREVERSIBLE TRANSFER?}

The EU has designed a highly sophišticated and consistent anti-trust system which has relied on the uniform and centralised nature of the relevant rules. Uniformity and centralisation are essential characteristics of EU competition rules for a number of reasons:
(1) to penetrate effectively national legal regimes;

(2) to create a consistent body of law;

(3) to establish the supremacy principle over national laws;

(4) to provide for quality legal instruments that produce unconditional binding effects throughout the EU.

The uniform nature of the European competition rules and their centralised application and enforcement are a strong indication of an irreversible transfer of anti-trust powers from member states to European institutions.

\section{THE EU ANTI-TRUST FRAMEWORK: A BRIEF ANALYSIS}

The EU anti-trust framework is based on a delicate system that balances effective supervision and control of restrictive practices and abusive dominance against simplified.administration. The laws carrying the EU's competition policy are built on a prohibition principle that pronounces all anti-competitive agreements between undertakings (cartels) void ab initio. However, when cartels contribute to the improvement of production or distribution of goods, or to the promotion of technical and economic progress and benefit consumers, the agreements which would otherwise have been void $a b$ initio may be exempted by the European Commission.

\section{The notification and authorisation process}

The control of restricted agreements under EU competition rules revolves around a notification and authorisation process that validates them ex ante. The Commission must be notified of agreements that might have adverse effects on competition within the EU. Such agreements are deemed void from the date of their conclusion. Upon notification, the Commission will analyse the economic implications of restrictive agreements and will authorise such agreements when satisfied that the pro-competitive elements of agreements outnumber the anti-competitive ones. Such an authority means that a restrictive agreement is deemed no longer to 
be void. This status begins at the date of notification of the agreement and not from the date of its conclusion. The Commission's authorisation is an administrative act, subject to the judicial review of the ECJ.

The authorisation process was put in place for three main reasons:

(1) the urgency of centralised logistics in awareness, information and market intelligence of economic operators within the EU;

(2) the need for legal certainty in the market place; and

(3) the importance of uniformity in application of competition law and policy.

However, centralisation in the application of competition law and policy and in particular the authorisation system attracted considerable criticism even from the early days of European integration. The main drawbacks of the authorisation process can be summarised as follows:

(1) the Commission's concerns that the notification and authorisation system is responsible for the leakage of serious violations of competition law which pass through the system unnoticed;

(2) the potential manipulation of the process by undertakings in order to avoid the jurisdictional competence of domestic competition authorities and national courts;

(3) undermined legal certainty in the market place as a result of the bureaucratically repetitive tasks of the Commission and the possibility of manipulative litigation blocking and exclusion of jurisdiction.

The European Commission has been aware of the above drawbacks of the authorisation process and the ex ante control of restrictive practices. It utilised the discretion given by the Treaty to introduce processes different to the notification and authorisation process, which aimed at reducing the administrative overloads and achieving a more effective supervision and control of restrictive agreements. As DG Competition gained experience in the economic assessment of notified agreements, the Commission introduced a de minimis rule through the publication of notices. If undertakings operated below certain turnover thresholds within the EU and if their agreements had an insignificant and non-appreciable effect upon competition they did not need to be notified. The evolution of the de minimis rule has eased the administrative workload of the Commission. For notifications above de minimis, the Commission also introduced a process where its economic assessment of a restrictive agreement was communicated to the undertakings concerned via a 'comfort letter'. Comfort letters are a swift method of evaluating the impact of a restrictive agreement without the need to proceed to the fully-fledged individual authorisation of the agreement by means of a negative clearance (administrative act of constitutive nature subject to judicial review). They have served the purpose of further easing the already overloaded notification backlog. However, their major flaw is their very nature; they are not administrative acts, such as negative clearance decisions, and cannot be used before judicial proceedings in a way other than addressing the Commission's non-binding views.

\section{THE EXCEPTION PROCESS}

The notification/authorisation system of ex ante control was deemed inadequate to cope with the growing European industrial base and its needs for competitiveness. Both the de minimis rule and the comfort letters were viewed as marginal improvements. The Commission was still responding to undertakings in a non-proactive way. Administrative workloads and the structural and behavioural changes of undertakings' relationships in the marketplace restricted application of EU competition law. Advanced vertical and horizontal relationships amongst undertakings, new ways of corporate interaction and an ever-growing experience and confidence of the Commission paved the way for the introduction of an exception. The exception process is complementary to the authorisation process. It has been put in place to provide for ex post exemption of certain categories of agreements from the prohibition principle. In other words, if an agreement meets certain criteria relating to its nature, structure and effect, it is automatically exempted from the prohibition principle. The exception process has developed from codification of individual authorisation decisions which reveal similarities. The exception process does not need any sort of authorisation from the Commission and is not subject to the judicial review of the ECJ.

The introduction of the exception process was made possible through a dynamic interpretation of the prohibition principle and a codified classification of individual authorisations. The Commission was able to provide for block exemptions of certain types of restrictive agreements between undertakings that fell under certain qualitative and quantitative criteria. Block exemption regulations were adopted and a considerable amount of restrictive agreements were brought into their remit, introducing an ex post control system without the need for notification and subsequent authorisation. The classified, determined and assessed types of agreements suitable for exception from the prohibitive nature of restrictive agreements also brought about an element of automation in the control system of anti-competitive behaviour. Such automation has shifted the onus of economic assessment. In the notification/authorisation process, it is the Commission's responsibility to assess the economic reasoning of a restrictive agreement in order to authorise 
it. However, under an exception process where the Commission provides the criteria for exemption in advance, undertakings concluding restrictive agreements are responsible for ensuring that their agreements fall under the remit of the exemption criteria.

\section{THE COMMISSION'S PROPOSALS FOR REFORMING PROCEDURAL COMPETITION LAWS}

The Commission has put forward two general options for the required consultation. The first covers the improvement of the notification/authorisation process. The second switches the existing procedural competition rules from the combined authorisation/exception process to a wholly exception process.

\section{The improvement of the authorisation process}

The first option can be achieved through a range of modifications to the existing procedural rules. It has certain advantages which deserve careful consideration by member states and European institutions in the light of the forthcoming legislative changes. The Commission accepts that the credibility and coherence of EU competition law and policy is attributed to the notification/authorisation process - despite its drawbacks - and the centralised application and control structure. A competition policy is credible because it can be endorsed and followed by interacting businesses and it must be coherent, predictable and consistent. Centralisation of the application of EU competition law and policy has contributed significantly towards its credibility and coherence. The main reason for this is that substantive EU anti-trust law is developed through a dynamic interpretation of Treaty provisions by the European Commission, and more importantly, through the approval of such interpretation by the ECJ and the court of first instance. Without the sole jurisdiction of the Commission, which has a high level of technical expertise and is guided by the judicial precedence of the ECJ, EU competition policy could not have achieved the same levels of maturity and quality.

\section{A RULE OF REASON: EVOLUTION NOT REVOLUTION IN ANTI-TRUST ASSESSMENT}

An important suggestion for improving the authorisation process is the development of a 'rule of reason' within the prohibition principle of restrictive agreements. The rule of reason is an evaluation and assessment by the Commission of the pro-competitive elements of restrictive agreements and their subsequent classification into broad but clearly defined categories of corporate behaviour. The aim is to waive their notification requirement and ease further the administrative duties of the Commission. The rule of reason can be seen as an expansion of the de minimis rule. Both processes, in principle, can result in the simplification of the authorisation process and in a dramatic fall of the notifications submitted to the Commission. However, the rule of reason in anti-trust has a number of disadvantages. It could undermine the integral structure of Article $81 \mathrm{EC}$ (control of cartels) (formerly Article 85 EC) by shifting the economic analysis on restrictive agreements outside the framework of the clearly defined existing categories of exception from the prohibition principle. That outcome appears undesirable and it might be ultra vires.

\section{A CENTRIFUGAL AUTHORISATION PROCESS}

This improved variation of the authorisation process largely accommodates the Commission's desire for decentralised application and enforcement of competition law and policy. Decentralisation of the authority to grant individual exemptions can be achieved by removing the Commission's sole jurisdictional competence to assess notified restrictive agreements and replacing it with a concurrent authorisation system based on a division of labour between the Commission and domestic competition authorities. This seems a very credible alternative to the substitution of sole jurisdiction of the Commission, while maintaining the authorisation process. Two ways have been forwarded in support of a 'centrifugal authorisation process'. The first recommends the substitution of the Commission's sole competence of assessing notifications with a process which weights the 'centre of gravity' (the Schwerpunktheorie developed by the Bundeskartellampt) of restrictive agreements, in order to allocate the responsibility for their assessment to either the Commission or the competent authority of the member state where the centre of gravity falls.

The Schwerpunktheorie envisages an assessment of the potential impact of restrictive practices prior to their notification and subsequent authorisation. Such assessment process does not remove the administrative burden of notifications, but it distributes the workload for authorisation. Apart from technical issues, there is the question of the enforceability of decisions by domestic authorities authorising restrictive practices. As the law stands currently, administrative decisions of domestic competition authorities authorising restrictive agreements can be enforced only within the territory of the respective member state. A possible problem arises if the centre of gravity of a restrictive agreement falls under the jurisdiction of a domestic competition authority but involves undertakings situated in different member states. A domestic decision has limited authority.

Another improvement to the authorisation process draws analogies and lessons from the Merger Control Regulation (MCR), which is based on criteria that determine the EU-wide or national dimension of anticompetitiveness. The MCR classifies mergers by reference to turnover thresholds. Thus, the corporate size of the 
prospective merger determines its exclusive jurisdictional forum of assessment. However, the jurisdictional division of powers based upon size criteria has a potential drawback: forum shopping and the so-called nationalisation of competition policy. The existence of multiple national jurisdictions and the possibility of the application of national laws may result in inconsistent decisions. This could be the start of forum shopping from undertakings seeking the most favourable outcome to their prospective agreement. Legal certainty would suffer and the credibility of the whole process could collapse. In addition, the jurisdictional plethora could be an incentive for domestic competition authorities to introduce domestic policy considerations in assessing anti-trust cases, a scenario that might lead to what the European Parliament described as the nationalisation of competition policy. Although forum shopping is a remote possibility primarily because of the principle of the supremacy of EU law and the on-going convergence of domestic legal systems, the introduction of domestic priorities into the competition policies of member states appears a probable outcome. Member states, when given discretion in applying their own rules, have been found to depart significantly from EU standards. A classical example of 'nationalised' policies can be found in the EU public procurement rules, where for decades the Commission has struggled to root out domestic priorities from a uniform and objective system used for the award of public contracts.

\section{PROCEDURAL SIMPLIFICATION OF NOTIFICATIONS AND AUTHORISATIONS - OPPOSITION PROCEDURES}

The existing procedures for notifications of restrictive agreements to the Commission are extremely complex and cumbersome. Their processing, consultation requirements, assessment, translation and publication take a significant proportion of the Commission's resources. The simplification of the procedural requirements relating to notifications can be further advanced by the parallel establishment of 'opposition procedures', as are currently in operation for types of restrictive agreements that fall into a 'grey area'. Opposition procedures give the Commission six months to oppose a restrictive agreement. When that period elapses without the Commission having opposed exemption, the agreement is deemed exempt. Procedural simplification and a widespread application of opposition procedures could considerably modify the notification/authorisation system. Their main disadvantage is their centralised nature and the limited opportunities for jurisdictional diversion to member states.

\section{ESTABLISHING A FULLY-FLEDGED EXCEPTION PROCESS}

The point of departure for the Commission's reform proposals is the decentralised application and enforcement of competition law and policy. For this purpose, the current notification/authorisation process must come to an end. The Commission clearly favours its replacement with an exception process that introduces an ex post control system of anti-competitive behaviour. The Commission appears confident that its obligations for effective supervision balanced with simplified administration can be met through an ex post control exception system. The mature and coherent competition policy built up through the notification and authorisation process and consistently applied by the Commission can now be dispersed by ex post exception control Undertakings would no longer have to notify agreements and seek authorisation; instead they have to make their own assessment on the compatibility of their restrictive agreements with EU law. The Commission claims that an ex post control process will relieve undertakings of the costly and cumbersome tasks of preparing notifications. However, under the new process, undertakings would have to take the responsibility of compliance themselves this will certainly cost as much as notifications. With the ex post control, the Commission intends to pass the onus of compliance to the market place, in an attempt to introduce a sort of self-regulation in anti-trust, where undertakings should themselves judge the potential adverse effects of their restrictive agreements.

\section{THE END OF AN ERA: ABOLISHING THE COMMISSION'S EXCLUSIVE JURISDICTION TO PROVIDE EXEMPTIONS}

The Commission proposes to relinquish its sole jurisdiction and competence for applying exceptions to the prohibition principle of EU competition law and to establish the parallel and concurrent competence of domestic authorities and national courts. This aim is the epitome of decentralisation in the application and enforcement of EU competition law and the ultimate objective of the Commission's reforms. Under the notification/authorisation process, the Commission is the sole jurisdictional authority to exempt restrictive agreements by assessing economically the pro and anticompetitive elements of restrictive agreements notified to it. Such exclusive powers preclude domestic competition authorities from examining restrictive agreements once they have been notified to the Commission. They also preclude national courts from proceeding with litigation before them.

Under the current authorisation process, the Commission's relationship with national courts is a constructive one, although it has been seriously constrained as a result of its exclusivity in providing exemptions. The ECJ has sent clear messages in establishing a very broad framework of co-operation between the Commission and national courts. The relationship between the Commission and national courts, according to the Court, should be based on the principle of the supremacy of EU law and the effort to avoid conflicting 
and inconsistent applications of EU competition law. However, the progress made by national courts in accepting their role as a parallel jurisdictional authority in anti-trust cases alongside the Commission has been disappointing. National courts, due to their general nature, often lack the technical capacity for the economic analysis required in anti-trust cases. Finally, the fact that a mere notification of a restrictive agreement to the Commission must result in the suspension of any litigation before national courts has a dissuasive effect upon the national court's wish to play an active role in the decentralised application and enforcement of EU competition law.

The Commission proposes the establishment of advanced information and co-operation procedures between itself and national courts to enable the latter to embrace their new role in anti-trust application and enforcement. Various models based on existing systems in domestic legal orders have been put forward which oblige national courts to supply information to the Commission every time they intend to apply EU competition law. This would allow the Commission to determine whether it wishes to intervene as an amicus curiae in national proceedings or to provide technical guidance to national courts with a view to maintaining consistency in the application and enforcement of EU competition law. Interestingly, the Commission might end up with notifications of litigation proceedings from national courts instead of notifications of restrictive agreements from undertakings.

Along the same lines, the Commission envisages close co-operation with domestic competition authorities. To achieve a parallel level of competence, competition authorities at both EU and national levels must be clear as to the division of labour and responsibilities amongst themselves. Existing guidance provides for a generic form of co-operation and information systems, but their main drawback surfaces every time the exclusivity of jurisdiction principle is invoked by the Commission as a consequence of a notification. A network of competition authorities, satellites to the Commission is necessary to replace the old system. In order to function in a compatible way with the Commission and within the proposed ex post control process of anti-competitive behaviour, such a network must be:

(1) empowered to have concurrent competence with the Commission in providing individual exemptions to the prohibition principle;

(2) entitled to determine the compatibility of restrictive agreements with block exemption regulations; and

(3) authorised to pass information between their members, including case-files or other confidential information that might be used in national legal or administrative proceedings.

The establishment of a network of competition authorities represents an enormous task for both the
Commission and member states. Administrative homogeneity is a pre-requisite for the successful functioning of such a network, with uniform examination and investigation procedures providing credibility. So far, domestic competition authorities have been established in eight member states, leaving seven national administrations with the task to complete the network. However, it is the quality of their decisions and the coherence in applying existing centrally formulated competition policy and judicial precedence that makes the Commission anxious rather than their formation. Critics fear that fifteen, initially, domestic competition authorities may introduce their own public policy considerations in their anti-trust decision-making, resulting in inconsistent and unpredictable results. The credibility of the network rests upon the same principles that have established the credibility of the current centralised policy: consistency, uniformity and legal certainty.

Both judicial and administrative decentralisation of competition law and policy reveal the need to approximate existing domestic legal and policy orders, as a transitional measure. This is necessary in order to avoid forum shopping and a parody of administrative decisions contradicting each other. Judgments by national courts, as well as decisions by domestic competition authorities, must produce legally binding effects outside the territory of the relevant member state. Considerable harmonisation will be required before the proposed decentralised system can produce outputs of similar quality to the existing centralised one.

\section{AUTOMATING THE EX POST EXCEPTION PROCESS: MORE BLOCK EXEMPTION REGULATIONS}

The Commission envisages adopting more block exemption regulations to encompass new types of agreements suitable for ex post exception. By doing so, it would diminish the need for undertakings to individually notify their agreements to the Commission or the domestic competition authorities. The Commission somehow wants to create an automated self-regulatory system of anti-competitive behaviour, where law and policy is to be determined centrally and their application and enforcement dispersed peripherally.

The enactment of more block exemption regulations to reduce the scope for individual notifications would have a significant effect in the decentralisation process. Regulations are capable of penetrating domestic legal order without any administrative intervention from member states, thus entrusting the national judiciary with the application and enforcement of rights and duties stipulated therein.

The Commission, finally, has proposed to intensify its investigatory powers. Under the current process, the judicial co-operation of member states must be sought before it can commence any investigation proceedings. This 
requirement has been laid down by the ECJ in order to safeguard the interests of the undertakings by ensuring that their investigation is authentic, not arbitrary or excessive. If the Commission utilises its investigatory powers in different member states, the simultaneous co-operation of the respective judiciaries could pose an insurmountable obstacle. National judges will authorise the Commission's intentions to investigate undertakings in their territory according to their existing (national) procedural laws. Inevitable delays, conflicting decisions and bureaucracy could derail the Commission's thrust to instigate investigations, by taking away any surprise element. It has been proposed to create a centralised jurisdictional authority to authorise single or multiple investigations by the Commission. It seems that the Commission with the one hand empowers national judiciaries to apply and implement EU competition law and with the other hand takes away their authority to safeguard the undertakings' constitutional rights prior to an anti-trust investigation. This should not be seen as a cynical power brokerage between central and peripheral anti-trust decision and policy making. Rather, it is an anomaly of a system in transition from centralised to centrifugal application.

The Commission's plan for enhanced investigatory powers finally include the right to summon to its own premises any person likely to be able to provide information relevant to an investigation. Similar powers exist in domestic competition authorities, subject to national procedural laws.

\section{CONCLUDING REMARKS}

This article has described the current structure of the application and enforcement of EU competition law and policy, the need for reform and the available options for such reforms, as well as illustrating the inherent advantages and disadvantages to these options. In the light of subsequent enlargement, the EU might be incapable of dispersing effectively its anti-trust law and policy, as the reactive nature of the notification/authorisation process and the bureaucracy associated with such process threatens to bring the whole system to a halt.

\section{The procedural reforms: modernisation or nationalisation}

The Commission's motives for modernisation of the procedural competition rules are genuinely pragmatic. Resource issues and the limited opportunity to decentralise the application and enforcement of EU competition rules appear as the two fundamental flaws of the existing notification/authorisation process. However, if the Commission wanted to, it could request more personnel, so its understaffed DG Competition could cope more efficiently with notifications and authorisation. The decentralisation question remains the focal point in the Commission's reform proposals. The only way to create a centrifugal process of parallel competence and concurrent jurisdiction would be, according to the Commission's view, to abandon the notification/authorisation process and the switch to a newly established ex post exception process.

The modernisation of EU competition law and policy through the empowerment of domestic authorities and building the capacity of national courts has, apart from the danger of inconsistencies in decisions and judgments, a major disadvantage in that it introduces national policies into the equation. The possible nationalisation of competition law and policy should be a concern for European institutions, as the Commission's reform proposals hardly address the danger of national policies playing a part in applying and enforcing EU competition law.

\section{Decentralisation: Ideology or necessity?}

How important is decentralisation in the application and enforcement of EU competition law and policy? If the effective modernisation of EU anti-trust laws were to stem from the proposed adoption of an ex post control process because of its decentralised application and enforcement, then a relevant modification of the existing ex ante authorisation process could also, theoretically, be capable of accommodating centrifugal application and enforcement.

In other words, it is not necessary to establish ex post control in order to achieve decentralisation. Therefore, decentralisation is not strictly speaking a necessary characteristic of the proposed ex post process, an assumption which reveals that the decentralisation of the EU competition law and policy is an ideological stance of the Commission rather than a necessity linked to the proposed ex post process.

It remains to be seen how European businesses would react to a decentralised ex post control of anti-competitive behaviour and whether the proposed changes would affect the confidence of the European industrial base and inhibit trade within the EU.

The proposals for the modernisation of Community Competition Law included in the White Paper have now been taken a step forward. A draft regulation has been presented by the European Commission, pointing out the future direction for the application and enforcement of anti-trust law and policy in the common market. Interestingly, in the proposed regulation, the Commission is standing strong for the basic principle which it has so vividly defended in the White Paper: the principle of decentralisation. The ideologically charged agenda of the Commission to establish a centrifugal anti-trust system in the common market is close to reality. 